\title{
Comparative study of some non-linear models for predicting the yield of Gmelina arborea plantation
}

\author{
F. O. Oboite ${ }^{1 *}$ and V. D. Ade-Oni ${ }^{2}$ \\ ${ }^{1}$ Department of Forestry and Wildlife, University of Benin, P.M.B. 1154, Benin City, NIGERIA \\ ${ }^{2}$ Department of Forest Production and Products, University of Agriculture, P.M.B.2373, Makurdi, NIGERIA \\ *Corresponding author. E-mail: Felixoboite@gmail.com
}

Received: June 03, 2014; Revised received: September 20, 2014; Accepted: December 02, 2014

\begin{abstract}
Yield models are important for effective forest management and as such were developed for the University of Benin Gmelina arborea plantation, Nigeria. The objectives of the study were to develop, evaluate and compare predictions from some non-linear models for timber volume estimation. A total of nine non-linear models comprising of three models each for weibull, logistic and log-normal models were developed using the three independent variables combinations (Basal area and merchantable height, diameter at base and merchantable height, diameter at middle and merchantable height). The assessment criteria (correlation coefficient $(R)$, coefficient of determination $\left(R^{2}\right)$, standard error of estimate $(S E)$ ) with the validation results (using percentage bias and probability plots of residuals) showed that all categories of weibull and logistic models generated in this study discovered to be very adequate for tree volume estimation. The highest $R^{2}(93.80)$, lowest SE (0.25) and lowest bias\% (1.29) in the study were achieved from Weibull model 1a. The log-normal models were the least adequate for tree volume estimation with the highest bias\%. The one way analysis of variance revealed that there were no significant differences in the performance of the non-linear models when varying predictor variables were used. The weibull, logistic models were therefore recommended for further use in this ecosystem and in any other forest ecosystem with similar site condition.
\end{abstract}

Keywords: Gmelina arborea, Plantation, Tectona grandis, Yield models

\section{INTRODUCTION}

Forest is long-lived dynamics biological systems that are continuously changing. It is often necessary to project these changes in order to obtain relevant information for sound decision making. In forestry, this information is acquired by means of forest inventories; systems for measuring the extent, quality and condition of forest (Husch et al., 2003). The main reason for conducting forest inventory either in the plantations or natural forest ecosystem is to estimate timber volume of the plots installed in the entire stand. For timber production, estimates of the growing stock are often expressed in terms of timber volume, which can be estimated from easily measurable dimensions of the tree. The most common procedure for volume estimation is to use volume equations, which are based on the relationship between volume and variables such as diameter, height etc. and other tree characteristics, which can be used in predicting tree volume. The assessment of stem volume is of high interest in forest management and is becoming of great global interest; for instance, in the context of Kyoto protocol rules, it is used in accounting for both absorbed and stored amount of $\mathrm{CO}_{2}$ by trees (Lindner and Karjalainen, 2007). According to Avery and Burkhart (2002), volume equations are used to estimate average content of standing trees of various sizes and species. The reliability of volume estimates depends on the range and extent of the available sample data, and how well volume equations fit this sample data.

The University forest plantation was originally established with the sole aim of teaching and research purposes and improving the conservation and maintenance of the soil productivity, but it is now used as a production forest without neglect to the original objectives. It is therefore important that information on present yield is always available for effective management and planning. The cost of remeasurement of trees is high and hence the use of models for estimating volume becomes important. In the light of this it is important to update inventories, predict future yield and to explore management alternatives and silvicultural options in order to provide information for decision-making. In view of these, information on models for predicting yield will be valuable for a sustainable forest management decision-making. For example, Forest resources managers require tree volume information to produce yield estimates for timber inventory and improve forest management decision-making (Peng,1999). The objective of this study was to develop, evaluate and compare some 
non-linear models for predicting the yield of University of Benin Gmelina arborea plantation.

\section{MATERIALS AND METHODS}

Study area: The G.arborea stand is located in the University of Benin Forest Plantation. However, this study covers an area of about 3.9 hectares of the forest plantation. The forest plantation is located between latitude $6.1^{\circ} \mathrm{N}$ to $6.8^{\circ} \mathrm{N}$ of the equator and $5.4^{\circ} \mathrm{E}$ to $6.0^{\circ} \mathrm{E}$ of the meridian (UNIBEN Master Plan, 1993). The Forest plantation is in the rainforest zone of Edo state, south-south, Nigeria. The rainforest is known for the bi-seasonal climate, which is the wet and dry season and it is generally moist because there is no prolonged period of drought. More importantly, precipitation usually exceeds or equals the potential evapotranspiration so that a shortage of soil moisture does not reasonably inhibit plant growth (Nwoboshi,1982). The university possesses an annual rainfall of $1500 \mathrm{~m}$. The humidity is also high and uniform ranging from $75 \%$ (afternoon) to $95 \%$ (morning). The topography of the area is gently slope eastward. The geology of the plantation consists of relatively thick layer of sedimentary sand and sandy clay of tertiary age (UNIBEN Master Plan, 1993). The sampling technique adopted for plot location is the systematic sampling. Seven sample plots were systematically selected from the G.arborea stand. The following tree data were collected in each sample plot: $\mathrm{dbh}$ (stem diameter at a position of $1.3 \mathrm{~m}$ above the ground level), diameters over bark at the base, middle and merchantable top, merchantable and total height.

Data analysis

Basal area calculation: The basal area of all trees in the sample plots were calculated using the formula:

$\mathrm{BA}=\left(\prod \mathrm{D}^{2}\right) / 4$

Where: $\mathrm{BA}=\mathrm{Basal}$ area $\left(\mathrm{m}^{2}\right), \mathrm{D}=$ Diameter at breast height $(\mathrm{cm}), \Pi=$ Pie $(3.142)$

Volume calculation: The volume of each tree was calculated in every plot using the Newton's formula:

$$
\pi H\left[\frac{D b^{2}+4 D m^{2}+D t^{2}}{24}\right]
$$

Where $\mathrm{V}=$ Stem volume $\left(\mathrm{m}^{3}\right), \mathrm{H}=$ Merchantable height $(\mathrm{m}), \mathrm{Db}=$ Diameter at the base, $\mathrm{Dm}=$ Diameter at the middle, $\mathrm{Dt}=$ Diameter at the top and $\pi=3.142$

Confidence limit (Upper and lower values): This is the range of values within which one mightexpect to find the parameter with same degree of assurance and was estimated as:

$\mathrm{CL}=$ Estimate (Volume/ha) $\pm \mathrm{t} \alpha / 2(\mathrm{SE})$

Where, SE is the standard error of estimate

Analysis of variance (ANOVA): One way analysis of variance(ANOVA) was carried out to investigate the significant difference in the yield models using various predictor variables (Model using basal area and merchantable height, model using diameter at the base and merchantable height, model using diameter at middle and merchantable height).

Non-Linear models

Weibull model: Ratkowsky (1983) and Myers (1986) employed weibull models in previous studies. The models is:

$$
\omega(t)=\left\{\alpha-\beta e^{-k t^{m}}\right\}+\varepsilon
$$

The model was modified for this study as:

$$
\mathrm{SV}=\beta_{0}\left\{1-e^{\beta_{1} \mathrm{X}-\beta_{2} \mathrm{MHT}}\right\}+\varepsilon
$$

\section{Logistic model:}

$$
\omega(t)=\alpha /\left(1+\beta e^{-k t}\right)+\varepsilon
$$

Nelder (1961), Oliver (1964)

The model was modified for this study as;

$$
\mathrm{SV}=\beta_{0} /\left(1+e^{\beta_{1} \mathrm{X}-\beta_{2} \mathrm{MHT}}\right)+\varepsilon
$$

Log-normal model: The probability density function of a log-normal distribution is:

Johnson et al., 1994.

The model was modified for this study as;

$$
\mathrm{SV}=\frac{\beta_{0}}{\mathrm{BA} B_{1} \sqrt{2 \pi}} e^{(\ln \mathrm{BA}-\mathrm{MHT})}
$$

Where SV=Stem Volume; MHT=Merchantable Height; $\mathrm{X}=$ Independent variable; $\beta_{0}, \beta_{1}$ and $\beta_{2}=$ parameters.

Stem volume was the predicted variable. The predictor variables include merchantable height, basal area, diameter at the base and diameter at the middle. The merchantable height was used for all models in the study but the basal area was surrogated with diameter at the base and diameter at the middle. This resulted in 3 model types

\section{Model 1: Weibull model:}

Model 1a: $\mathrm{SV}=\mathrm{b}_{0}\left(1-\mathrm{e}^{-\mathrm{b} 1 \mathrm{BA}-\mathrm{b} 2 \mathrm{MHT}}\right)$

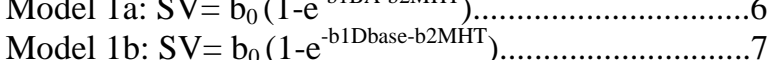

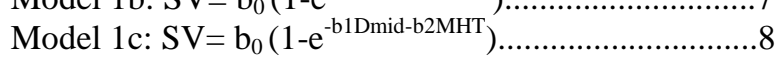

Model 2: Logistic model:

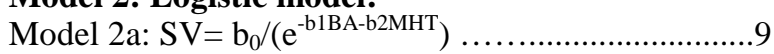

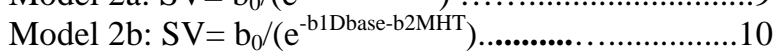

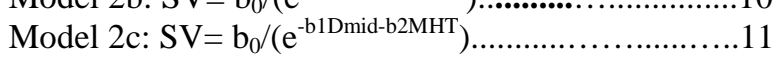

Model 3: Log-normal model

Model 3a: $\mathrm{SV}=1 /\left(\mathrm{BAb}_{0} \sqrt{2} \prod\right) \mathrm{e}^{(\mathrm{InBA}-\mathrm{b} 2 \mathrm{MHT})} \ldots \ldots \ldots \ldots . . . .12$

Model 3b: $\quad \mathrm{SV}=1 /\left(\right.$ Dbaseb $\left._{0} \sqrt{2} \prod\right) \mathrm{e}^{(\text {InDbase-b2MHT) }} \ldots \ldots . . .13$

Model 3c: $\quad S V=b_{0} /\left(\right.$ Dmidb $\left._{1} \sqrt{2} \prod\right) \mathrm{e}^{(\text {InDmid-b2MHT })} \ldots \ldots . . . .14$

Where: $b_{0}, b_{1}, b_{2}=$ Regression constants to be estimated, $\mathrm{E}=$ The exponential constant (Euler's value $=2.71$ ), 
$\mathrm{BA}=$ Basal area $\left(\mathrm{m}^{2}\right), \mathrm{MHT}=$ Merchantable Height, $\mathrm{D}_{\text {base }}=$ Diameter at the base, $\mathrm{D}_{\text {mid }}=$ Diameter at the middle, $\mathrm{SV}=$ Stem volume $\left(\mathrm{m}^{3}\right)$.

All these models are intrinsically nonlinear regression models.

Assessment of the models: The volume models were assessed with the view of recommending those with good fit for further uses. The following statistical criteria will be used: Significance of regression (F-ratio), multiple correlation coefficient $(\mathrm{R})$, coefficient of determination $\left(\mathrm{R}^{2}\right)$.

Validations of the models: This was achieved by comparing the models' output with values observed on the field. The validation process examines the usefulness or validity of the models (Marshall and Northway, 1993). The entire field data were divided into two sets. The first set (calibrating set) and the second the validation set. The calibrating set is used to construct the models while the validation set is used to test them. To test the accuracy of the yield models, the models were estimated with $20 \%$ of the plots randomly selected from the 20 plots available. The model was then used to predict the state of the remaining plots at the time of their current measurement, given their state at the previous inventory. For models with good fit, the intercept must be close to 0 and the slope close to 1 , the model must be significant and highly correlated, coefficient of determination value must be very high and the standard of error of estimate must be small values (Onyekwelu and Akindele, 1995; Adekunle et al., 2004).

Percentage bias estimation: The absolute percentage difference (\% bias) was determined by dividing the difference between volumes obtained with Newtons formula (observed volume) and models output by the same observed volume and multiplied by 100 .

$\%$ Bias $=(\mathrm{Vp}-\mathrm{Vo}) / \mathrm{Vo}$

Where: $\mathrm{V}_{\mathrm{o}}=$ The observed volume, $\mathrm{V}_{\mathrm{p}}=$ The predicted volume (models output).

The value must be relatively small for the model to be acceptable for management purpose.

\section{RESULTS AND DISCUSSION}

Preliminary analysis: Descriptive statistics for the $G$. arborea stand (Table 1) showed that basal area ranged from $0.076 \mathrm{~m}^{2}$ to $0.230 \mathrm{~m}^{2}$, stem volume ranged from $0.820 \mathrm{~m}^{3}$ to $3.600 \mathrm{~m}^{3}$, merchantable height ranged from 6.57 to $17.07 \mathrm{~m}$ and diameter at breast height ranged from $0.23 \mathrm{~m}$ to $1.70 \mathrm{~m}$. The mean stem volume, mean basal area and mean merchantable height were $1.473 \mathrm{~m}^{3}, 0.106 \mathrm{~m}^{2}$ and $14.447 \mathrm{~m}$, respectively.

Assessment of models: All weibull models in the study (Table 2) were discovered to have good fit even when different independent variables (Basal area, diameter at the base and diameter at the middle) were used. This is as a result of the high correlation coefficient $(\mathrm{R})$ and coefficient of determination $\left(\mathrm{R}^{2}\right)$ values, small standard error of estimate and significant f-ratio ( $\mathrm{p}<0.05$ ) obtained. The $\mathrm{R}^{2}$ and $\mathrm{R}$ values for the models in the $G$. arborea stand were 0.926 and 0.962 (model 1a), 0.856 and 0.925 (model $1 \mathrm{~b}$ ) and 0.811 and 0.900 (model 1c), respectively. The standard error (SE) ranged from 0.005 to 0.551 . The logistic models in the study (Table 3) was discovered to also have good fit. The $\mathrm{R}^{2}$ and $\mathrm{R}$ values recorded for the logistic models were 0.720 and 0.849 (model 2a), 0.700 and 0.837 (model 2b) and 0.598 and 0.774 (model 2c), respectively. The SE of estimate ranged from 0.001 to 2.096. However, the log-normal models (Table 4) had an $\mathrm{R}^{2}$ and $\mathrm{R}$ values of 0.321 and 0.567 (model $1 \mathrm{a}$ ), 0.297 and 0.545 (model $3 b$ ) and 0.220 and 0.469 (model 3c), respectively. The SE ranged from 0.004 to 3.869 .

Comparative assessment and validation of models types with varying predictive variables: The comparative assessment of the performance of the various model type (Basal area, diameter at base and diameter at middle) used in developing the non-linear equations (Weibull, logistic, log-normal) is showed in table 5. It was observed that there was no significant difference in the performance of yield prediction for three models combinations (Basal area and merchantable height, diameter at base and merchantable height, diameter at middle and merchantable height) for each of weibull, logistic and log-normal models at 5\% level of significance. Generally, the highest value of percentage biases when the output of each model was compared with the observed volume was $28.262 \%$ (model $3 b$ ) across all the models (Table 6). For the weibull models, the range of the bias (\%) was $1.290,3.327$ and 2.648 for model $1 \mathrm{a}, 1 \mathrm{~b}$ and $1 \mathrm{c}$, respectively. The logistic model had the values of bias (\%) ranged from 1.426 (model $2 \mathrm{c}$ ) to 3.870 (model $2 \mathrm{~b}$ ) while for the log-normal models, the percentage biases were 17.719 (3a), 28.262 (3b), 11.81(3c).

According to Adekunle (2007) non-linear models were discovered to be very adequate for yield estimation in lowland rainforest ecosystem. This is a further confirmation to the use of non-linear models in this study. The assessment criteria revealed that all weibull and logistic models were very suitable for tree volume estimation in the plantation except the log-normal models. These models were similar to those used by Yaoxiang et al. (2011) for Predict Stem Cumulative Biomass of Standing Trees and Yevide et al.,(2014) for some plantation species also. In their studies, age was used as independent variable as Vanclay (1994) noted that there is no best method for forest growth models, this study therefore surrogated age with basal area, diameter at the base and middle. VanderSchaaf (2008) also replaced age with diameter and height during model generation in their studies. The indices of fit, which are the coefficient of multiple correlation and coefficient of determination ( $R$ and $R^{2}$, respectively), for all models except the log-normal models were very high. During validation with simple linear regression equations (comparison of models outputs with 
Table 1. Descriptive statistics for the G. arborea stand.

\begin{tabular}{lccccc}
\hline Variables & Mean & Minimum & Maximum & SD & SE \\
\hline THT & 17.2691 & 9.4000 & 20.8200 & 3.9065 & 0.2215 \\
MHT & 14.4471 & 6.5700 & 17.0700 & 3.5056 & 0.1988 \\
BA & 0.1059 & 0.0760 & 0.2300 & 0.3761 & 0.0213 \\
DB & 0.6121 & 0.3300 & 1.1450 & 0.5033 & 0.0285 \\
DM & 0.2698 & 0.1700 & 0.5100 & 0.2399 & 0.0136 \\
DT & 0.1173 & 0.0774 & 0.3200 & 0.1726 & 0.0098 \\
SV & 1.4730 & 0.8200 & 3.6000 & 0.1827 & 0.0104 \\
CD & 6.2457 & 4.0873 & 12.2319 & 3.9044 & 0.2214 \\
DBH & 0.3194 & 0.2300 & 1.7000 & 0.2784 & 0.0158 \\
\hline
\end{tabular}

THT- Total height; MHT- Merchantable height; BA- Basal area; DB- Diameter at base; DM-Diameter at middle; DT-Diameter at top; SV - Stem volume; CD- Crown diameter; DBH- Diameter at breast height; CL- Crown length; CR- Crown ratio; SLC- Slender coefficient

Table 2. Weibull models for G.arborea stand.

\begin{tabular}{llccccc}
\hline S.N. & Models & Parameter & Estimates & SE & t-value & P-level \\
\hline $1 \mathrm{a}$ & $\mathrm{SV}=\mathrm{b}_{0}\left(1-\mathrm{e}^{-\mathrm{b} 1 \mathrm{BA}-\mathrm{b} 2 \mathrm{MHT}}\right)$ & $\mathrm{B}$ & 0.853 & 0.056 & 43.023 & 0.002 \\
& $\mathrm{R}^{2}=0.926, \mathrm{R}=0.962$ & $\mathrm{~b}_{1}$ & 2.509 & 0.502 & 13.045 & 0.000 \\
& & $\mathrm{~b}_{2}$ & 0.006 & 0.551 & 5.023 & 0.000 \\
$1 \mathrm{~b}$ & $\mathrm{SV}=\mathrm{b}_{0}\left(1-\mathrm{e}^{-\mathrm{b} 1 \mathrm{Db} \text { base-b2MHT }}\right)$ & $\mathrm{B}$ & 0.225 & 0.017 & 52.455 & 0.000 \\
& $\mathrm{R}^{2}=0.856, \mathrm{R}=0.925$ & $\mathrm{~b}_{1}$ & 1.384 & 0.061 & 4.512 & 0.000 \\
& & $\mathrm{~b}_{2}$ & -0.009 & 0.005 & 12.199 & 0.000 \\
$1 \mathrm{c}$ & $\mathrm{SV}=\mathrm{b}_{0}\left(1-\mathrm{e}^{-\mathrm{b} 1 \mathrm{Dmid}-\mathrm{b} 2 \mathrm{MHT}}\right)$ & $\mathrm{Bo}$ & 0.090 & 0.456 & 63.824 & 0.000 \\
& $\mathrm{R}^{2}=0.811, \mathrm{R}=0.900$ & $\mathrm{~b}_{1}$ & 2.417 & 0.078 & 5.240 & 0.000 \\
& & $\mathrm{~b}_{2}$ & 0.004 & 0.051 & 6.034 & 0.000 \\
\hline
\end{tabular}

$\mathrm{SV}=$ Stem volume, $\mathrm{BA}=$ Basal area, $\mathrm{MHT}=$ Merchantable height,Dbase=Diameter at the base, Dmid= Diameter at the middle, $\mathrm{SE}=$ Standard Error of Estimates and $\mathrm{b}_{0}, \mathrm{~b}_{1}, \mathrm{~b}_{2}=$ Parameter.

Table 3. Logistic models for G.arborea stand.

\begin{tabular}{llccccc}
\hline S.N. & Models & Parameter & Estimates & SE & t-value & P-level \\
\hline $2 \mathrm{a}$ & $\mathrm{SV}=\mathrm{b}_{0} /\left(\mathrm{e}^{-\mathrm{blBA-b2MHT}}\right)$ & $\mathrm{B}$ & 0.631 & 2.096 & 79.023 & 0.000 \\
& $\mathrm{R}^{2}=0.720, \mathrm{R}=0.849$ & $\mathrm{~b}_{1}$ & 4.435 & 1.245 & 6.240 & 0.000 \\
& & $\mathrm{~b}_{2}$ & 0.012 & 0.481 & 12.561 & 0.000 \\
$2 \mathrm{~b}$ & $\mathrm{SV}=\mathrm{b}_{0} /\left(\mathrm{e}^{-\mathrm{b} 1 \mathrm{Db} \text { ase-b2MHT }}\right)$ & $\mathrm{B}$ & 0.263 & 0.017 & 114.309 & 0.000 \\
& $\mathrm{R}^{2}=0.700, \mathrm{R}=0.837$ & $\mathrm{~b}_{1}$ & 1.412 & 0.241 & 3.218 & 0.000 \\
& & $\mathrm{~b}_{2}$ & 0.004 & 0.002 & 13.274 & 0.000 \\
$2 \mathrm{c}$ & $\mathrm{SV}=\mathrm{b}_{0} /\left(\mathrm{e}^{-\mathrm{b} 1 \mathrm{Dmid}-\mathrm{b} 2 \mathrm{MHT}}\right)$ & $\mathrm{Bo}$ & 3.069 & 0.076 & 72.800 & 0.000 \\
& $\mathrm{R}^{2}=0.598, \mathrm{R}=0.774$ & $\mathrm{~b}_{1}$ & 2.940 & 0.013 & 4.390 & 0.000 \\
& & $\mathrm{~b}_{2}$ & -0.022 & 0.001 & 12.450 & 0.000 \\
\hline
\end{tabular}

$\mathrm{SV}=$ Stem volume, $\mathrm{BA}=$ Basal area, $\mathrm{MHT}=$ Merchantable height, Dbase=Diameter at the base, Dmid $=$ Diameter at the middle, $\mathrm{SE}=$ Standard Error of Estimates and $\mathrm{b}_{0}, \mathrm{~b}_{1}, \mathrm{~b}_{2}=$ Parameter. 
Table 4. Log-normal models for G. arborea stand.

\begin{tabular}{|c|c|c|c|c|c|c|}
\hline S.N. & Models & Parameter & Estimates & $\overline{\text { SE }}$ & t-value & P-level \\
\hline \multirow[t]{3}{*}{$3 a$} & $\mathrm{SV}=\mathrm{b}_{0} /\left(\mathrm{BAb}_{1} \sqrt{2} \prod\right) \mathrm{e}^{(\mathrm{InBA}-\mathrm{b} 2 \mathrm{MHT})}$ & Bo & 0.688 & 3.166 & 13.750 & 0.000 \\
\hline & $\mathrm{R}^{2}=0.321, \mathrm{R}=0.567$ & $b_{1}$ & 3.518 & 0.887 & 9.824 & 0.000 \\
\hline & & $\mathrm{b}_{2}$ & 0.011 & 0.605 & 4.093 & 0.000 \\
\hline \multirow[t]{3}{*}{$3 b$} & $\mathrm{SV}=\mathrm{b}_{0} /\left(\right.$ Dbaseb $\left._{1} \sqrt{ } 2 \prod\right) \mathrm{e}^{(\text {InDbase-b2MHT })}$ & Bo & 0.168 & 3.092 & 62.300 & 0.000 \\
\hline & $\mathrm{R}^{2}=0.297, \mathrm{R}=0.545$ & $b_{1}$ & 2.633 & 7.869 & 4.502 & 0.000 \\
\hline & & $\mathrm{b}_{2}$ & -0.017 & 1.094 & 11.095 & 0.000 \\
\hline \multirow[t]{3}{*}{$3 c$} & $\mathrm{SV}=\mathrm{b}_{0} /\left(\mathrm{Dmidb}_{1} \sqrt{ } 2 \prod\right) \mathrm{e}^{(\mathrm{InDmid}-\mathrm{b} 2 \mathrm{MHT})}$ & Bo & 7.108 & 0.021 & 97.237 & 0.000 \\
\hline & $\mathrm{R}^{2}=0.220, \mathrm{R}=0.469$ & $\mathrm{~b}_{1}$ & 4.319 & 0.032 & 8.028 & 0.000 \\
\hline & & $\mathrm{b}_{2}$ & -0.002 & 0.501 & 23.237 & 0.000 \\
\hline
\end{tabular}

$\mathrm{SV}=\mathrm{Stem}$ volume $\mathrm{BA}=\mathrm{Basal}$ area, $\mathrm{MHT}=$ Merchantable height,Dbase=Diameter at the base, Dmid= Diameter at the middle, $\mathrm{SE}=$ Standard Error of Estimates and $\mathrm{b}_{0}, \mathrm{~b}_{1}, \mathrm{~b}_{2}=$ Parameter.

Table 5. ANOVA table showing the level of significant differences between the models types used in fitting the non-linear models.

\begin{tabular}{|c|c|c|c|c|c|c|}
\hline Models & & Sum of squares & df & Mean Square & $\mathbf{F}$ & Sig. \\
\hline \multirow[t]{3}{*}{ Weibull } & Model Type & 0.108 & 2 & 0.054 & 1.432 & $0.241 \mathrm{~ns}$ \\
\hline & Error & 8.395 & 223 & 0.038 & & \\
\hline & Total & 8.503 & 225 & & & \\
\hline \multirow[t]{3}{*}{ Logistic } & Model Type & 0.091 & 2 & 0.045 & 1.873 & $0.156 \mathrm{~ns}$ \\
\hline & Error & 5.409 & 223 & 0.024 & & \\
\hline & Total & 5.500 & 225 & & & \\
\hline \multirow[t]{3}{*}{ Log-normal } & Model Type & 0.031 & 2 & 0.016 & 0.775 & $0.462 \mathrm{~ns}$ \\
\hline & Error & 4.460 & 223 & 0.020 & & \\
\hline & Total & 4.491 & 225 & & & \\
\hline
\end{tabular}

Table 6. Validation results and \% bias of the Weibull models with simple linear regression model.

\begin{tabular}{lccccccc}
\hline Models & $\mathbf{b}_{\mathbf{0}}$ & $\mathbf{b}_{\mathbf{1}}$ & $\mathbf{R}$ & $\mathbf{R}^{\mathbf{2}} \mathbf{( \% )}$ & $\mathbf{S E}$ & Predicted volume & Bias (\%) \\
\hline $1 \mathrm{a}$ & -0.067 & 4.356 & 0.969 & 93.80 & 0.254 & $1.492 \pm 0.14$ & 1.290 \\
$\mathrm{1b}$ & -0.043 & 2.765 & 0.866 & 74.98 & 0.318 & $1.424 \pm 0.23$ & 3.327 \\
$\mathrm{1c}$ & -0.075 & 1.095 & 0.855 & 73.04 & 0.630 & $1.434 \pm 0.37$ & 2.648 \\
$2 \mathrm{a}$ & -0.058 & 3.656 & 0.908 & 82.46 & 0.254 & $1.441 \pm 0.34$ & 2.172 \\
$2 \mathrm{~b}$ & -0.136 & 6.344 & 0.900 & 81.09 & 0.318 & $1.416 \pm 0.31$ & 3.870 \\
$2 \mathrm{c}$ & -0.092 & 2.455 & 0.837 & 70.03 & 0.630 & $1.452 \pm 0.13$ & 1.426 \\
$3 \mathrm{a}$ & -0.067 & 4.356 & 0.885 & 78.40 & 0.254 & $0.212 \pm 0.43$ & 17.719 \\
$3 \mathrm{~b}$ & -0.043 & 2.765 & 0.876 & 76.67 & 0.318 & $0.204 \pm 0.39$ & 28.262 \\
$3 \mathrm{c}$ & -0.075 & 1.095 & 0.715 & 51.06 & 0.630 & $0.299 \pm 0.42$ & 11.813 \\
\hline
\end{tabular}

observed volume), the intercepts $\left(b_{\mathrm{o}}\right)$ were very close to zero while the slope coefficients were very close to 1. Also, the index of fit, $R$ and $R^{2}$ values were high and significant F-ratio at $\mathrm{P} \leq 0.05$ was obtained. The standard error of estimate is a good measure of overall predictive value of regression equations (Akindele and LeMay, 2006). It is also a common measure of goodness of fit in nonlinear regression models (Glantz and Slinker, 2001), with low values indicating better fit. In view of the above, among the non-linear models, Weibull and logistic model gave the best volume predictions for G.arborea stands. When compared with observed volume, weibull model 1a (basal area and merchantable height) best predicted the yield. Other 
variable combination using weibull also gave close estimates of the yield prediction. This therefore means that diameter at the middle and other growth variables should be considered in further studies when developing models for yield prediction. Although the result of the one way analysis of variance showed that there was no significant difference $(\mathrm{P}>0.05)$ in fitting different independent variables in the non-linear models. This might be due to the fact that variation in diameter at various points (taper) on an individual tree is small as a result of the uniform spacing and even aged stands that characterized the forest plantation in the study. This would be revealed if further studies are carried out in a natural forest.

\section{Conclusion}

Non-linear models for volume estimation was developed and validated for $G$. arborea at the University of Benin forest plantation. The tree growth data were collected from sample plots in the study area. Based on the evaluation of the models examined in this study the weibull and logistic models were found to be more suitable and fit for volume prediction. However the best timber volume predictions was achieved from weibull model 1a. The log-normal models which gave the three highest bias\% were the least adequate for yield estimation of the three models. Development of statistical models for growth and yield relationships of economic tree species is an essential preliminary step towards the implementation of sustainable forest management. The yield models developed in this study gave reasonable precise estimates of volume and is recommended for use in the management of the University of Benin Plantation and will serve as a framework for future data collection, management and analysis.

\section{REFERENCES}

Adekunle, V.A.J. (2007). Non-linear regression models for timber volume estimation in natural forest ecosystem, Southwest Nigeria. Research Journal of Forestry, 1: 4054.

Adekunle, V.A.J., Akindele, S.O. and Fuwape, J.A. (2004). Structure and yield models for tropical lowland rainforest ecosystem of South West Nigeria. Food. Agric. Environ., 2: 395-399.

Akindele, S.O. and Le May, V.M. (2006). Development of tree volume equations for common timber species in the tropical rainforest area of Nigeria. For. Ecol. Manage., 226: 41-48.

Avery, T.E. and Burkhart, H.E. (2002). Forest Measurements. 5th Edn., McGraw Hill, New York, pp: 456.

Glantz, S.A. and Slinker, B.K. (2001). Primer of applied regression and analysis of variance. $2^{\text {nd }}$ ed. McGraw-Hill.
Husch, B., Charles, I. M and Thomas, W. B. (2003). Forest Mensuration. New York, U.S.A.: The Ronald Press Company. pp 120-123 International,Wallingford, UK.

Johnson, Norman L.; Kotz, Samuel; Balakrishnan, N. (1994), "14: Lognormal Distributions", Continuous univariate distributions. Vol. 1, Wiley Series in Probability and Mathematical Statistics: Applied Probability and Statistics (2nd ed.), New York: John Wiley \& Sons, ISBN 978-0-471-58495-7, MR 1299979

Lindner, M. and Karjalainen, T. (2007). Carbon inventory methods and carbon mitigation potentials of forests in Europe: a short review of recent progress. European Journal of Forestry Research, 126: 149-156.

Marshall, P.L. and Northway (1993). Suggested minimum procedure for validation of growth and yield model: Growth and yield estimation from successive forest inventories. Proceedings of the IUFRO World Congress, 1993, Copenhagen, pp: 281-281.

Myers, R.H. (1986). Classical and modern regression with applications.Duxubury Press, Boston. 359p.

Nelder, J.A. (1961). The fitting of a generalization of the logistic curve. Biometrics 17: 89-110.

Nwoboshi, L.C. (1982).Tropical Silviculture (Principles and techniques) Ibadan University Press Publishing house University of Ibadan,Ibadan,Nigeria 333pp.

Oliver, F.R. (1964). Methods of estimating the logistic function. Applied statistics 13: 57-66.

Onyekwelu, J.C. and Akindele, S.O. (1995). Stand volume equation for Gmelina arborea plantation in Oluwa forest reserve, Nigeria. Nig. J. For., 25:92-95.

Peng, C. (1999). Nonlinear height-diameter models for nine boreal forest tree species in Ontario.Ministry of Natural Resources. Ont. For. Res. Inst., Sault Ste Marie, ON, For. Res. Rep No. 155. 28 pp.

Ratkowsky, D.A. (1983). Nonlinear regression modeling. Marcel Dekker, New York. 276 p.

University of Benin (1993): Master Plan. University of Benin Printing Press. 360 pp.

Vanclay, J. (1994). Modelling Forest Growth and Yield: applications to mixed tropical forests. $\mathrm{CAB}$ International. UK. 312 p.

VanderSchaaf C. (2008). Compatible Stem Taper and Total Tree Volume Equations for Loblolly PinePlantations in Southeastern Arkansas. Journal of the Arkansas Academy of Science, 62:103-106.

Yaoxiang L., Lichun J. and Mingyu L. (2011). A Nonlinear Mixed-Effects Model to Predict Stem Cumulative Biomass of Standing Trees. 2011 3rd International Conference on Environmental Science and Information Application Technology ESIAT 2011. Volume 10, Part A, 2011, Pages 215-221.

Yevide A.,Ganglo J., Glelekakai R., Decanniere C., Fonton N.(2014). Growth modeling of short rotation coppice teak ( Tectona grandis L.f) stands in Republic of Bénin. International Journal of Advanced Agricultural Research 2: 58-66. 